\title{
Expression, Purification, and Functional Characterization of Atypical Xenocin, Its Immunity Protein, and Their Domains from Xenorhabdus nematophila
}

\author{
Jitendra Singh Rathore \\ School of Biotechnology, Gautam Buddha University, Yamuna Expressway, Greater Noida, Uttar Pradesh 201308, India \\ Correspondence should be addressed to Jitendra Singh Rathore; jitendra@gbu.ac.in
}

Received 30 April 2013; Revised 17 July 2013; Accepted 1 August 2013

Academic Editor: Rodrigo E. Mendes

Copyright ( 12013 Jitendra Singh Rathore. This is an open access article distributed under the Creative Commons Attribution License, which permits unrestricted use, distribution, and reproduction in any medium, provided the original work is properly cited.

\begin{abstract}
Xenorhabdus nematophila, a gram-negative bacterium belonging to the family Enterobacteriaceae is a natural symbiont of a soil nematode from the family Steinernematidae. In this study cloning, expression, and purification of broad range iron regulated multidomain bacteriocin called xenocin from $X$. nematophila ( $66 \mathrm{kDa}$, encoded by $x c i n A$ gene) and its multidomain immunity protein $\left(42 \mathrm{kDa}\right.$, encoded by $x i m B$ gene) have been done. $x$ cinA-ximB $\left(\mathrm{N}^{\prime}\right.$ terminal $\left.270 \mathrm{bp}\right)$, translocation, and translocationreceptor domain of $x \operatorname{cin} A, x i m B$, and its hemolysin domain were cloned, expressed, and purified by single step Ni-NTA chromatography under native conditions. In the functional characterization, neutralization of $x c i n A$ toxicity by immunity domain of $x i m B$ gene was determined by endogenous assay. Exogenous toxic assays results showed that only the purified recombinant xenocin-immunity domain $(10 \mathrm{kDa})$ protein complex had toxic activity. Atypical cognate immunity protein $(42 \mathrm{kDa})$ of xenocin was fusion of immunity domain $(10 \mathrm{kDa})$ and hemolysin domain $(32 \mathrm{kDa})$. In silico analysis of immunity protein revealed its similarity with hemolysin and purine NTPase like proteins. Hemolytic activity was not observed in immunity protein or in its various domains; however, full-length immunity protein lacking Walker motif showed ATPase activity. Finally, using circular dichroism performed secondary structural analyses of all the recombinant proteins/protein complexes.
\end{abstract}

\section{Introduction}

Bacteriocins are toxins produced by the bacteria to inhibit the growth of similar or closely related bacterial strain(s) during stress conditions [1]. They are structurally, functionally, and ecologically diverse, produced by almost all major lineages of Eubacteria and Archaebacteria [2]. Ribosomal encoded bacteriocins are generally secreted in the extracellular milieu by the producers where they recognize specific receptors on the surface of susceptible or target cells. They induce toxicity in the target cells by different mechanisms like enzymatic nuclease (DNase or RNase) or pore formation in cytoplasmic membrane [3]. Their structure comprises of three distinct domain organizations: (i) a domain involved in recognition of specific receptor R, (ii) a domain involved in translocation $\mathrm{T}$, and (iii) a domain responsible for their toxic activity C. Molecular mass of ribosomal encoded bacteriocins vary from $\sim 25$ to $80 \mathrm{kDa}$ and are broadly classified into two groups, group A and B, based on their cross-resistance [4]. These proteins have received increasing attention due to their potential use as preservatives in the food industry or in the therapeutic applications for clinical usage [5].

Xenorhabdus nematophila is a motile gram-negative bacterium belonging to the family Enterobacteriaceae, and forms a symbiotic association in the gut of soil nematode from the family Steinernematidae $[6,7]$. Free-living forms of the bacterium have not yet been isolated from soil or water sources, which suggests that the symbiotic association may be essential for the survival of the bacteria in the environment. Nematodes enter the insect hemocoel via different routes. Infective juvenile (IJs) enters digestive tract of the insect larva and subsequently penetrates into hemocoel of the host insect. The nematode can also gain access to the hemocoel via the respiratory spiracles or by penetrating directly through insect 
cuticle [8]. Bacteria, in turn, are essential for effective killing of the insect host and are required by the nematode to complete its life cycle $[8,9]$. X. nematophila can be grown under standard laboratory conditions. Growth in vitro is probably supported by the rich nutrient supply of the laboratory growth media and lack of competition that normally exists in the soil environment. As the bacteria enter stationary phase of growth cycle, they secrete several extracellular products, which include lipase(s), phospholipase(s), and protease(s), and several broad spectrum antibiotics that can be assayed in the culture media $[10,11]$. These extracellular products are believed to be secreted in the insect hemolymph when the bacteria enter stationary phase. These degradative enzymes break the macromolecules from insect cadaver to provide the developing nematode with nutrient supply, while the antibiotics suppress contamination of the cadaver by other microorganisms. Cytoplasmic inclusion bodies, composed of highly expressed crystalline proteins, are also produced by the bacterium during stationary-phase growth [12]. In our earlier study we have identified iron regulated bacteriocin from $X$. nematophila known as xenocin [13]. Recombinant xenocinimmunity protein complex is toxic to six bacterial genus like Bacillus, Enterobacter, Enterococcus, Citrobacter, Serratia, and Stenotrophomonas [13]. Xenocin-immunity protein complex has atypical features which include the following. (1) Tol box which has been replaced by Ton box from $\mathrm{N}^{\prime}$ terminal end of translocation domain of xenocin [13]. (2) There is only $30 \%$ similarity of xenocin with other bacteriocins [13]. (3) Size of its cognate immunity protein is $42 \mathrm{kDa}$, whereas $10-16 \mathrm{kDa}$ have been reported in other prokaryotic systems [4]. Immunity protein of $X$. nematophila is a fusion of two different domains, immunity domain and hemolysin domain.

(4) Immunity protein has ATPase activity, although Walker motif is missing in its primary amino acid sequence. (5) Xenocin-immunity protein complex is secretory in nature without any signal sequence.

In this study we have cloned, expressed, and purified all the possible domains of $x \operatorname{cin} A$ and $x i m B$ genes. Neutralization of $x \operatorname{cin} A$ toxicity by immunity protein domain is determined by endogenous assay. Exogenous toxicity assays were performed with purified recombinant xenocin-immunity domain protein complex and other domains. In silico study of the immunity protein showed its similarity with hemolysin and purine NTPase like protein; therefore, hemolysis and ATPase assays were performed. Finally, secondary structural analysis of recombinant xenocin-immunity domain protein complex, catalytic-immunity domain protein complex, immunity protein, and its hemolysin domains were performed with circular dichroism.

\section{Material and Methods}

2.1. Bacterial Strain, Media, and Culture Conditions. All the chemicals were purchased from Sigma (Sigma-Aldrich) except where otherwise mentioned. Ligase and endonucleases were purchased from Promega (Madison, USA). Vector pGEM-T easy was procured from Promega (Madison, USA). Vector pQE30, Ni-NTA agarose resin and QIA quick spin

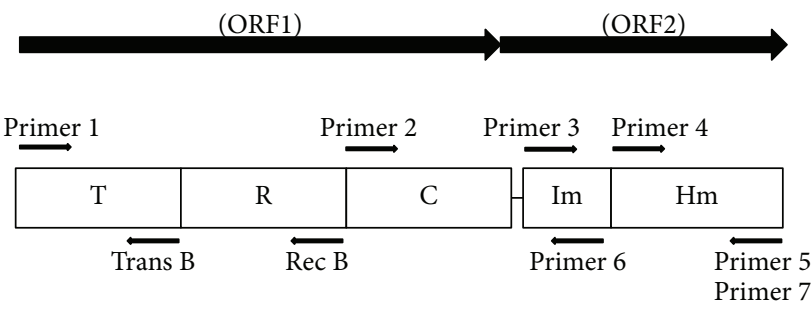

(a)

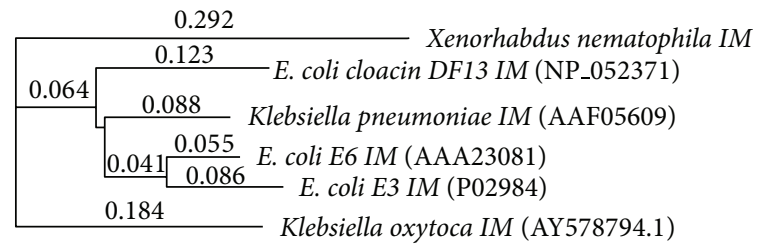

$\stackrel{0.05}{\longmapsto}$

(b)

FIGURE 1: (a) Domain map of xenocin and immunity protein. T: translocation domain; R: receptor domain; C: catalytic domain of xenocin; Im: immunity domain; Hm: hemolysin domain of immunity protein. Primers position and orientation for cloning of different domains depicted with arrows. (b) Phylogenetic analysis of immunity protein from $X$. nematophila with similar protein sequences from other bacterial species. E. coli cloacin DF13 (NP_052371); Klebsiella pneumonia (AAF05609); E. coli colicin-E6 (AAA23081); E. coli E3 (P02984); Klebsiella oxytoca (AY578794.1).

columns were from Qiagen (Germany). Oligonucleotides were custom synthesized by Sigma. E. coli strains DH $5 \alpha$ (Bethesda Research Laboratories) were used as the host for cloning. E. coli BL 21(DE3) pLysS strain from Novagen and M 15 strain from Qiagen were used in the expression studies. The plasmid vector pGEM-T Easy from Promega (Madison, USA) were used for PCR cloning. LB medium was used for growing bacterial strains. Ampicillin, Kanamycin, and Chloramphenicol were used in the concentration of 100, 35, and $25 \mu \mathrm{g} \mathrm{mL}{ }^{-1}$, respectively.

2.2. Phylogenetic Analysis. Phylogenetic analysis of immunity protein was done by a method as described earlier [14]. Briefly, amino acids of all the protein sequences that matched with immunity protein were aligned by CLUSTALW (Mac vector 7.0), and a tree was constructed using neighbourjoining method, with the best tree mode in the Mac vector version 7.0 (Oxford Molecular, England) program.

\subsection{Cloning}

2.3.1. Xenocin-Immunity Domain. Primer pairs used for cloning studies are shown in Figure 1(a). All the constructs were amplified from the $4.3 \mathrm{~kb}$ genomic DNA fragment of $X$. nematophila. The ORF 1 encoding $x$ cinA gene and partial ORF 2 encoding immunity domain of $x i m B$ gene were obtained by PCR amplification using primer 1 with a $\mathrm{BamHI}$ site at the $5^{\prime}$ end and a reverse primer 6 with HindIII site at the $3^{\prime}$ end. The amplified product $(2 \mathrm{~kb})$ was ligated in pGEM-T 
Easy and pQE30 vector, producing pJC5 and pJC6 plasmids, respectively.

2.3.2. Catalytic-Immunity Domain. The catalytic domain (318 bp) of $x$ cin $A$ gene was cloned with the immunity domain (first $270 \mathrm{bp}$ of $x \mathrm{imB}$ gene) of $x \mathrm{imB}$ gene using primer pair 2 and 6 as described earlier [13].

2.3.3. Translocation Domain of Xenocin. Primer 1 with a $\mathrm{BamHI}$ site at the $5^{\prime}$ end and a reverse primer TransB with NcoI site at the $3^{\prime}$ end were used to amplify the translocation domain of $x$ cinA gene. Amplified product of $1 \mathrm{~kb}$ was ligated in pGEM-T Easy vector and pQE30 vector, producing pJC7 and $\mathrm{pJC} 8$ plasmids, respectively.

2.3.4. Translocation-Receptor Domain of Xenocin. Primer 1 with a BamHI site at the $5^{\prime}$ end and a reverse primer RecB with HindIII site at the $3^{\prime}$ end were used to amplify the translocation-receptor domain of $x$ cinA gene. The amplified product $(1.5 \mathrm{~kb})$ was ligated in pGEM-T Easy vector and pQE30 vector producing $\mathrm{pJC} 9$ and $\mathrm{pJC10}$ plasmids, respectively.

2.3.5. Immunity and Its Hemolysin Domain. Primer 3 with BamHI site at the $5^{\prime}$ end and a reverse primer 5 with HindIII site at the $3^{\prime}$ end used for $x i m B$ cloning and forward primer 4 without any restriction site and backward primer 7 without any restriction site were used for cloning $x i m B$ hemolysin domain. The amplified products of $1 \mathrm{~kb}$ and $700 \mathrm{bp}$ were ligated in pGEM-T Easy vector producing pJC11 and pJC12 plasmids. The $1 \mathrm{~kb}$ amplified product was further ligated in pQE30 and $700 \mathrm{bp}$ amplified product was ligated in pQE31 expression vector producing $\mathrm{pJC13}$ and $\mathrm{pJC14}$ plasmids, respectively.

2.3.6. Cloning of XcinA-XimB (255 bp) Gene(s) under Native Promoter. A $2.330 \mathrm{~kb}$ DNA fragment containing both $x c i n A$ and immunity domain of $x i m B$ gene with native promoters was amplified using XenocinF1 (300 bp upstream of start codon of $x$ cinA locus) and primer 6 and cloned in pGEM-T Easy vector producing pXIM construct. The empty pGEMT Easy vector designated as pGEM was used as control. Both plasmids were transformed in DH5 $\alpha$ cells. The XIM and GEM strains were used for endogenous assays. All the constructs and strains are listed in Table 1.

2.4. Expression and Purification. The plasmids pJC6, pJC8, pJC10, pJC13, and pJC14 were transformed in M15 cells where as pJC4 was transformed in E. coli BL 21(DE3) pLysS cells. The resulting strains JC4, JC6, JC8, JC10, JC13, and JC14 were used for expression and purification of recombinant proteins under the control of IPTG inducible T7 promoter as per the protocol described earlier [13]. Briefly, overnight grown cultures were diluted 100 fold in fresh $50 \mathrm{~mL}$ LB medium and grown till the $\mathrm{OD}_{600}$ reached 0.5. Culture was induced by adding $1 \mathrm{mM}$ final concentration of IPTG and incubated at $30^{\circ} \mathrm{C}$ for 6 hours. Cells were harvested and washed with $40 \mathrm{~mL}$ of cold and $50 \mathrm{mM}$ sodium phosphate buffer, $\mathrm{pH} 8$, containing $300 \mathrm{mM} \mathrm{NaCl}$ and $50 \mathrm{mM}$ benzamidine (buffer A). The cell pellet was suspended in $25 \mathrm{~mL}$ of buffer $\mathrm{A}$ and cells were disrupted by sonication at $4^{\circ} \mathrm{C}$. The cell lysate was centrifuged at $12000 \times \mathrm{g}$ for $30 \mathrm{~min}$ at $4^{\circ} \mathrm{C}$ in a $\mathrm{RC} 5$ plus centrifuge, and the 6XHis-tagged recombinant proteins or protein complexes in the soluble fractions were purified as follows. The supernatant from the previous step was loaded on Ni-NTA agarose column preequilibrated with buffer A at $4^{\circ} \mathrm{C}$. The column was washed extensively with buffer A, containing $25-50 \mathrm{mM}$ imidazole, and the protein/protein complex was eluted with buffer A containing $300 \mathrm{mM}$ imidazole. Fractions containing pure protein or protein complex were concentrated using centricon (Millipore PM10). Recombinant protein or protein complexes were dialyzed overnight against 100 volumes of $50 \mathrm{mM}$ sodium phosphate buffer, $\mathrm{pH}$ 8 , and the final preparations were stored at $-20^{\circ} \mathrm{C}$ in the presence of $15 \%$ glycerol.

2.5. Endogenous Assay. To study the neutralizing effect of the immunity domain protein, $x c i n A$ gene was cloned with its native promoter along with immunity domain of $x \mathrm{im} B$ gene which gave rise to pXIM. This construct was transformed in E. coli DH5 $\alpha$ to give rise to XIM strain. Empty pGEM$\mathrm{T}$ Easy vector was considered as control and transformed in E. coli $\mathrm{DH} 5 \alpha$ to give rise to GEM strain. Overnight grown strains GEM and XIM were subcultured in fresh medium and incubated till the $\mathrm{OD}_{600}$ reached 0.5. The cultures were diluted in fresh medium $1: 100$ and induced with $0.3 \mu \mathrm{g} \mathrm{mL}^{-1}$ of mitomycin C (an inducer of xenocin native promoter). The optical densities of the cultures were monitored at $600 \mathrm{~nm}$ during different intervals.

2.6. Exogenous Toxicity Assay. The bacteriostatic activity of purified recombinant proteins/complexes were determined by the protocol as described earlier [13]. Briefly, LB agar plates without antibiotics were overlaid with $3 \mathrm{~mL}$ of soft nutrient agar containing indicator $E$. coli $\mathrm{DH} 5 \alpha$ strain grown in M9 medium, and the protein complex was applied to sterile disks. The plates were incubated overnight at $37^{\circ} \mathrm{C}$, and the sizes of clearance zones were recorded.

2.7. Hemolytic Activity Analysis. Freshly isolated rabbit blood cells were washed thrice with phosphate buffer saline (PBS) by centrifuging at $1000 \times \mathrm{g}, 4^{\circ} \mathrm{C}$ for 10 minutes. Washed erythrocytes were resuspended in PBS to make a final concentration of $4 \%$. The same volume $(100 \mu \mathrm{L})$ of protein $(5 \mu \mathrm{M})$ sample dissolved in PBS and erythrocytes suspension were added into wells of 96-well plate. PBS and water was used to establish 0 and $100 \%$ hemolysis, respectively. The plate was then incubated at $37^{\circ} \mathrm{C}$ for $1 \mathrm{hr}$ and centrifuged at $1000 \times \mathrm{g}$ for 5 minutes. The resulting supernatant was transferred to new wells, and the absorbance was determined at $540 \mathrm{~nm}$ on a continuous spectrum microtitre plate reader.

2.8. ATPase Assay with Immunity Protein and Its Domains. ATPase assay was performed with recombinant immunity protein and its domains. Protein samples of different concentrations were incubated with $0.2 \mu \mathrm{Ci}$ of $\left[\gamma_{-}{ }^{32} \mathrm{P}\right]$ labelled 
TABLE 1: Strains and plasmids used in this study.

\begin{tabular}{|c|c|c|}
\hline Construct/strain & Characteristic & Source \\
\hline E. coli $\mathrm{DH} 5 \alpha$ & supE44 $\Delta$ lacU169 hsdR17 recA1 endA1 gyrA96 thi-1 relA1Ф80 dlacZ $\Delta \mathrm{M} 15$ & Invitrogen \\
\hline E. coli M 15 & $\mathrm{NaI}^{\mathrm{S}} \mathrm{Str}^{\mathrm{S}} \mathrm{RIF}^{\mathrm{S}} \mathrm{Thi}^{-} \mathrm{Lac}^{-} \mathrm{Ara}^{+} \mathrm{Gal}^{+} \mathrm{MtI}^{-} \mathrm{F}^{-} \mathrm{RecA}^{+} \mathrm{Uvr}^{+} \mathrm{Lon}^{+}$ & Qiagen \\
\hline $\begin{array}{l}\text { E. coli BL21 (DE3) } \\
\text { pLysS }\end{array}$ & $\mathrm{F}^{-}$omp $\mathrm{T} h s d \mathrm{~S}_{\mathrm{B}}\left(r_{B}{ }^{-} m_{B}{ }^{-}\right)$galdcm(DE3)pLysS $\left(\mathrm{Cm}^{\mathrm{R}}\right)$ & Novagen \\
\hline pGEM-T Easy & $3 \mathrm{~kb}$ vector for cloning PCR fragments; $\mathrm{Amp}^{\mathrm{r}}$ & Promega \\
\hline pQE30 and 31 & $3.4 \mathrm{~kb}$ expression vector; $\mathrm{Amp}^{\mathrm{r}}$ & Qiagen \\
\hline pET $28(a)$ & $5.3 \mathrm{~kb}$ expression vector; $\mathrm{kan}^{\mathrm{r}}$ & Novagen \\
\hline pJC2/JC2 & pQE30 containing $(x \operatorname{cin} A)$ and $x i m B$ genes. & Ref. [13] \\
\hline $\mathrm{pJC} 4 / \mathrm{JC} 4$ & pET28 containing catalytic domain and 270 bp partial $x i m B\left(\mathrm{~N}^{\prime}\right.$ terminal 86 amino acids $)$ & Ref. [13] \\
\hline $\mathrm{pJC5} / \mathrm{JC} 5$ & pGEM-T Easy containing $x \operatorname{cin} A$ and $x i m B(255 \mathrm{bp})$ genes & This study \\
\hline pJC6/JC6 & pQE30 containing $x$ cin $A$ and $x i m B(255 \mathrm{bp})$ genes & This study \\
\hline $\mathrm{pJC7/JC7}$ & pGEM-T Easy containing translocation domain of $x c i n A$ gene & This study \\
\hline $\mathrm{pJC} 8 / \mathrm{JC} 8$ & pQE30 containing translocation domain of $x$ cinA gene & This study \\
\hline pJC9/JC9 & pGEM-T Easy containing translocation-receptor domain of $x c i n A$ gene & This study \\
\hline pJC10/JC10 & pQE30 containing translocation-receptor domain of xcinA gene & This study \\
\hline pJC11/JC11 & pGEM-T Easy containing $x i m B$ gene & This study \\
\hline pJC12/JC12 & pGEM-T Easy containing hemolysin domain of $x i m B$ gene & This study \\
\hline $\mathrm{pJC13/JC13}$ & pQE30 containing $x i m B$ gene & This study \\
\hline pJC14/JC14 & pQE31 containing hemolysin domain of $x i m B$ gene & This study \\
\hline pXIM/XIM & pGEM-T Easy containing $x$ cin $A$ (with native promoter) and $x i m B(255 \mathrm{bp}$ ) genes & This study \\
\hline pGEM/GEM & pGEM-T Easy in E. coli $\mathrm{DH} 5 \alpha$ & This study \\
\hline
\end{tabular}

ATP $(6000 \mathrm{Ci} / \mathrm{mmol}$, PerkinElmer Life Sciences, USA) in a buffer containing $20 \mathrm{mM}$ Tris- $\mathrm{HCl}$ ( $\mathrm{pH} \mathrm{8.0),} 1 \mathrm{mM} \mathrm{MgCl}_{2}$, $100 \mathrm{mM} \mathrm{KCl}, 8 \mathrm{mM} \mathrm{DTT}$, and $80 \mu \mathrm{g} / \mathrm{mL}$ of BSA in a total reaction volume of $10 \mu \mathrm{L}$. Samples were incubated at $37^{\circ} \mathrm{C}$ for 30 minutes. At the end of the reaction, $1 \mu \mathrm{L}$ of the reaction mixture was spotted on a polyethyleneimine thinlayer chromatography (TLC) plate (Sigma-Aldrich, USA) and air-dried. Chromatography was performed using $0.5 \mathrm{M} \mathrm{LiCl}$ and $1 \mathrm{M} \mathrm{HCOOH}$ as the running solvent. The TLC paper was air-dried and autoradiographed.

2.9. Circular Dichroism. The far-UV CD spectrum was recorded between 190 and $260 \mathrm{~nm}$ (500 $\mu \mathrm{L}$ sample volume) on a Jasco J-810 spectropolarimeter equipped with a Jasco Peltier temperature controller at $25^{\circ} \mathrm{C}$ using $1 \mathrm{~mm}$ optical path length quartz cells and the step size was $0.5 \mathrm{~nm}$ with $1 \mathrm{~nm}$ bandwidth at a scan speed of $20 \mathrm{~nm}$ minute ${ }^{-1}$. Averages of 5 scans were obtained for blank and protein spectra, and the data was corrected for buffer contribution. Measurement was performed at protein concentration of $1 \mu \mathrm{M}$ under nitrogen flow. The secondary structure percentages were calculated using $\mathrm{K} 2 \mathrm{~d}$ computer modelling program. The results were expressed as mean residue ellipticity in units of degree $/ \mathrm{cm}^{2} / \mathrm{dmol}^{1}$.

\section{Results}

Phylogenetic analysis of the xenocin [14] and its immunity protein was done by preparing phylogenetic tree, using neighbour-joining method. Results showed that immunity protein formed a separate cluster in the very beginning as shown Figure 1(b). Attempt was made to express $x$ cin $A$ gene alone but transformants were not obtained. Further, $x \operatorname{cin} A$ gene was cloned along with $\mathrm{N}^{\prime}$ terminal immunity domain $(10 \mathrm{kDa})$ of $x \mathrm{im} B$ gene. Purification of recombinant xenocin-immunity domain $(10 \mathrm{kDa})$ protein complex from JC6 strain was done by Ni-NTA chromatography under native conditions. Two bands were visible in SDS-PAGE. One was at the position corresponding to $66 \mathrm{kDa}$ and another below $14 \mathrm{kDa}$ protein marker as shown in Figure 2(a) which corroborates with the size of xenocin and immunity domain of immunity protein, respectively. The yield of purified recombinant xenocin-immunity domain protein complex was $60 \mathrm{mg} / \mathrm{L}$. Purification of recombinant catalytic-immunity domain protein complex with Ni-NTA chromatography under native conditions from JC4 strain [13] also showed two bands corresponding to the size of catalytic domain of $x \operatorname{cin} A$ and immunity domain of $x i m B$ as shown in Figure 2(b). The yield of purified recombinant catalytic-immunity domain protein complex was $100 \mathrm{mg} / \mathrm{L}$. Purification of recombinant translocation domain of $x$ cinA gene from JC8 strain with Ni-NTA chromatography showed multiple bands in SDSPAGE as shown in Figure 2(e). Further, western blot was performed using purified fraction, probed with anti-His antibody, and the result showed single band at $38 \mathrm{kDa}$ which corresponds to the size of recombinant translocation domain protein as shown in Figure 2(f). Purification of recombinant translocation-receptor domain protein with Ni-NTA chromatography from JC10 strain showed two prominent bands 


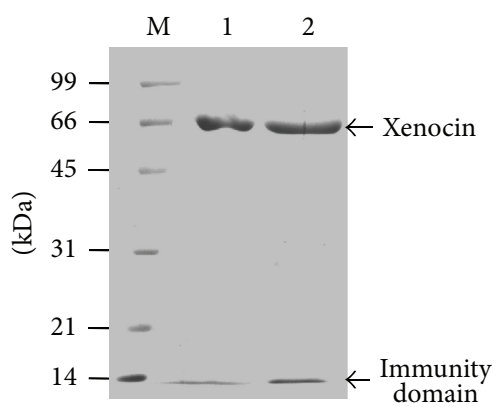

(a)

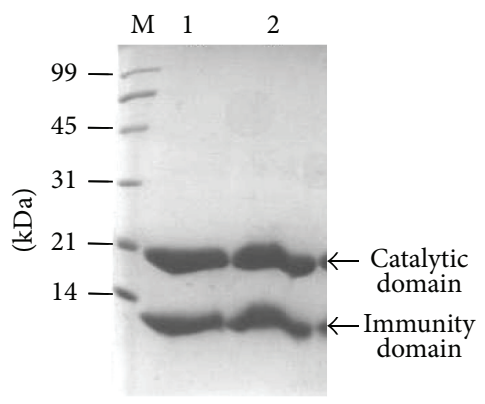

(b)

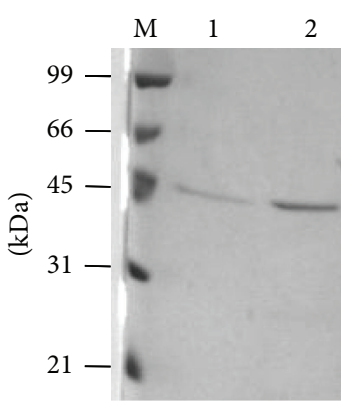

(c)

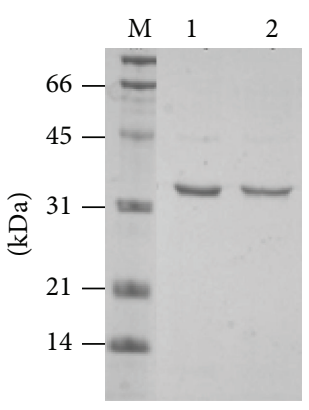

(d)

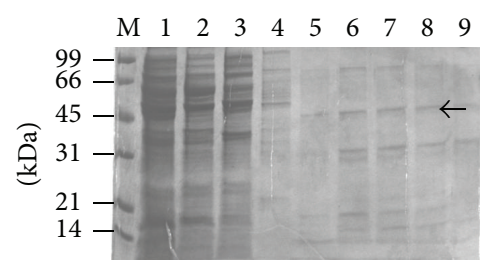

(e)

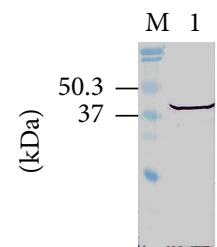

(f)

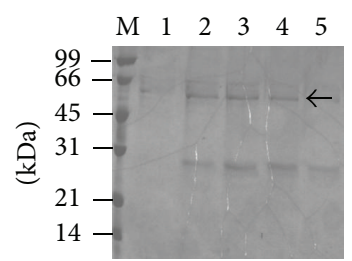

(g)

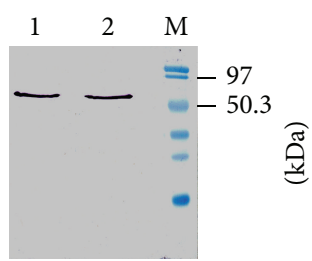

(h)

FIGURE 2: SDS-PAGE showing purification of recombinant proteins or protein complexes by Ni-NTA chromatography under native conditions. (a) Purification of xenocin-immunity domain $(10 \mathrm{kDa})$ protein complex. Lane M: protein marker; lanes 1 and 2: purified fractions. (b) Purification of catalytic-immunity domain protein complex. Lane M: protein marker; lanes 1 and 2: purified fractions. (c) Purification of full length immunity protein $(42 \mathrm{kDa})$. Lane M: protein marker; lanes 1 and 2: purified fractions. (d) Purification of hemolysin domain $(32 \mathrm{kDa})$. Lane M: protein marker; lanes 1 and 2: purified fractions. (e) SDS-PAGE showing expression and purification of translocation domains of xcinA gene by Ni-NTA chromatography. Lane M: protein marker; lane 1: induced cells; lane 2: uninduced supernatant; lane 3: induced supernatant; lane 4: Wash 1; lanes 5 to 9: fraction number 2 to 6 . Arrow indicates the purified translocation domain. (f) Western blot analysis of translocation domain with purified fraction using anti-His antibodies. Lane M, Prestained protein marker; Lane 1: purified sample. (g) SDS-PAGE showing the purification of translocation-receptor domains of $x$ cinA gene by Ni-NTA chromatography. Lane M: protein marker; lanes 1 to 5: fraction number 3 to 7 . Arrow indicates the expression and purification of translocation-receptor domain. (h) Western blot analysis of translocation-receptor domain with anti-His antibodies. Lane 1: induced cells; lane 2: Ni-NTA purified protein; Lane 3: prestained protein marker.

in SDS-PAGE. Upper band corresponded to $\sim 52 \mathrm{kDa}$ whereas lower band corresponded to $\sim 28 \mathrm{kDa}$ as shown in Figure 2(g). Western blot was performed using whole cell lysate and the purified fraction, probed with anti-His antibody, which showed a single band at $52 \mathrm{kDa}$ corresponding to a size of recombinant translocation-receptor domain protein as shown in Figure 2(h). Purification of recombinant full length immunity protein, as well as its hemolysin domain protein from JC13 and JC14 strains, showed less but stable expression as shown in Figures 2(c) and 2(d), respectively. The yield of purified recombinant immunity protein and its hemolysin domain was $28 \mathrm{mg} / \mathrm{L}$ and $30 \mathrm{mg} / \mathrm{L}$, respectively.

Neutralization of endogenous toxicity of $x$ cin $A$ by immunity domain of $x i m B$ gene was determined by endogenous assay. Endogenous assay with XIM strain (harboring pXIM containing $x c i n A$ with its native promoter and first 85 amino acid residues of $x$ im $B$ gene) and GEM strain (harboring empty pGEM T-Easy vector) in the presence of mitomycin C showed the same growth profile as shown in Figure 3(a).

Exogenous toxicity assay was performed with purified recombinant xenocin-immunity domain $(10 \mathrm{kDa})$ complex using E. coli DH5 $\alpha$ as target cells. The zone of inhibition was observed as shown in Figure 3(b) (i). Purified catalyticimmunity domain protein complex was used to study for the bacteriostatic effect in the exogenous assays. The zone of inhibition was not observed in this case as shown in
Figure 3(b) (ii). Similar results were observed when full length immunity protein $(42 \mathrm{kDa})$ encoded by $x \mathrm{im} B$ gene or its hemolysin domain $(32 \mathrm{kDa})$ was used for exogenous assay as shown in Figure 3(b) (iii) and (iv), respectively. Moreover, as expected zone of inhibition was not observed in buffer control experiment as shown in Figure 3(b) (v).

Protein-protein blast results (http://www.ncbi.nlm.nih .gov/BLAST/) of the immunity protein showed its similarity with hemolysin (AAF42109) and purine NTPase like protein (data not shown). Hemolytic assay with fresh rabbit red blood cells was performed with purified full length immunity protein as well as its immunity and hemolysin domain. Results showed that none of the protein had hemolytic activity (data not shown).

ATPase assay was performed with purified recombinant full length immunity protein, its immunity domain, and hemolysin domain. ATPase activity was not detected in recombinant immunity domain, hemolysin domain protein, and even in the purified BSA which was used as negative control as shown in Figure 4(a) lane 1. However, full length recombinant immunity protein $(42 \mathrm{kDa})$ showed ATPase activity with increasing concentration of protein and was comparable to the ATPase activity of purified GroEL protein of $X$. nematophila which was used as the positive control, as shown in Figure 4(a) lane 2. 


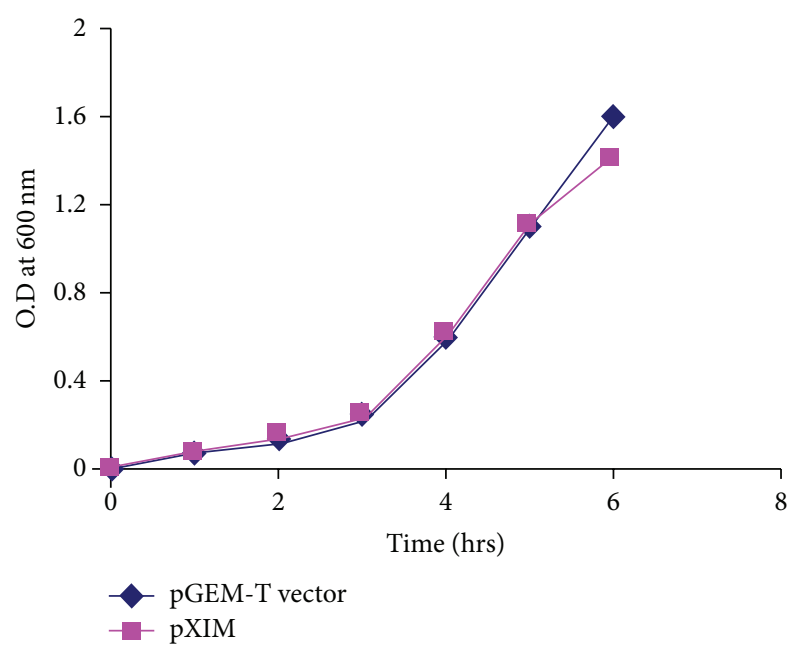

(a)

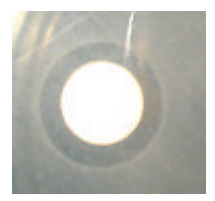

(i)

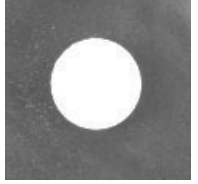

(ii)

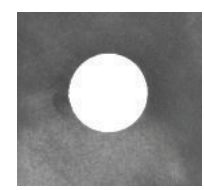

(iii)

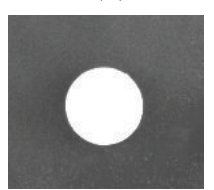

(iv)

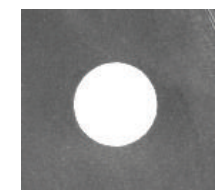

(v)

(b)

FIGURE 3: Neutralization of endogenous toxicity of xenocin expressed under its native promoter in the presence of mitomycin C. (a) Bacterial growth was monitored by determining the optical density at $600 \mathrm{~nm}$; (匹): XIM strain induced; ( $\uparrow)$ : GEM strain induced. (b) Exogenous toxicity assay using E. coli DH5 $\alpha$ grown in M9 medium as target cells. (i) Purified recombinant xenocin-immunity domain protein complex; (ii) purified recombinant catalytic-immunity domain protein complex; (iii) purified recombinant immunity protein (42 kDa); (iv) purified recombinant hemolysin domain $(32 \mathrm{kDa})$ of immunity protein; (v) buffer control.

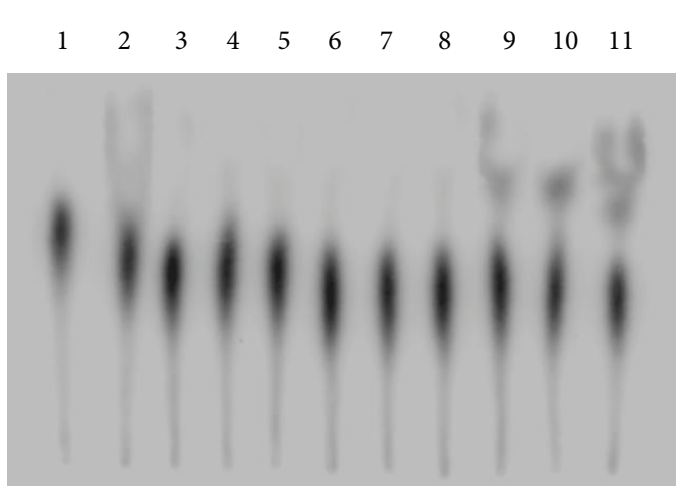

(a)

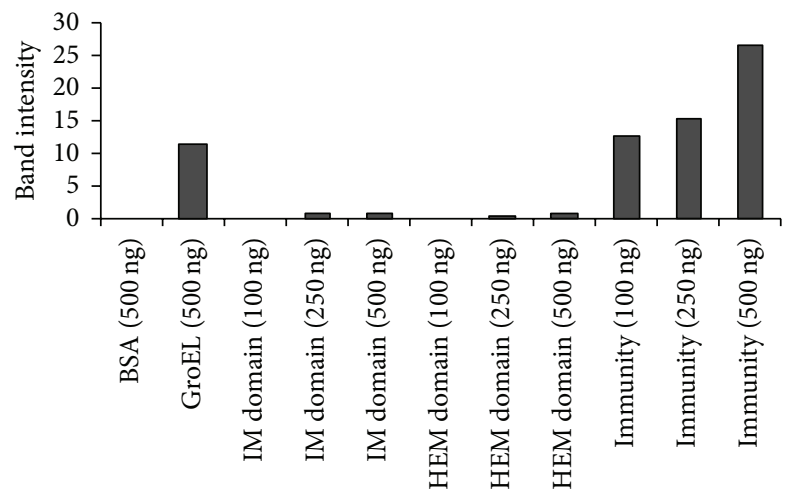

(b)

Figure 4: (a) ATPase assay with immunity domain $(10 \mathrm{kDa})$, hemolysin domain $(32 \mathrm{kDa})$, and full length immunity protein (42 kDa). (a) Lane 1: BSA (500 ng, negative control); lane 2: Gro EL (500 ng, positive control). Lane 3: immunity domain (100 ng); lane 4: (250 ng); and lane 5, (500 ng): Lane 6: hemolysin domain (100 ng); lane 7 (250 ng) and lane 8: (500 ng). Lane 9: immunity protein (100 ng); lane 10 (250 ng) and lane 11: (500 ng). (b) Histogram prepared by IMAGE J software on the basis of band intensity.

The far UV spectra of purified recombinant xenocinimmunity domain $(10 \mathrm{kDa})$ protein complex, catalyticimmunity domain protein complex, immunity, and its hemolysin domain were recorded at $25^{\circ} \mathrm{C}$ as shown in Figure 5. Recombinant xenocin-immunity domain protein complex was found to contain $41 \% \alpha$-helical structure and $21 \% \beta$-sheet. Catalytic-immunity domain protein complex was found to contain $51 \% \beta$-sheet and only $7 \% \alpha$-helical structure. In case of full length immunity protein $30 \%$ of the secondary structure was $\alpha$-helical whereas $13 \%$ was $\beta$-sheet. Hemolysin domain of the immunity protein also had the same secondary conformation with $30 \% \alpha$-helical and $11 \% \beta$-sheet content.

\section{Discussion}

Recombinant xenocin-(66 kDa-) immunity $(42 \mathrm{kDa})$ protein complex has a broad range bacteriostatic property, inhibiting the growth of six insect gut resident bacterial species [13]. Due to only $30-31 \%$ primary sequence similarity with other bacteriocins, xenocin from the $X$. nematophila forms a distinct cluster in phylogenetic tree [14]. Phylogenetic analysis of immunity protein showed similar results, in which immunity protein from $X$. nematophila forms a separate cluster in the very beginning. This could be due to variable length of immunity protein from $X$. nematophila. Cognate immunity 


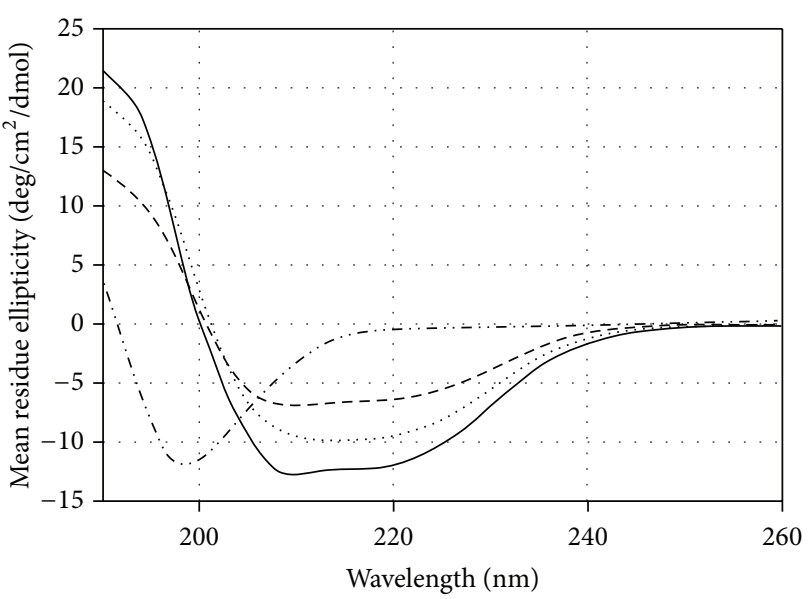

- Xenocin-immunity domain complex ..... Immunity

-... Catalytic-immunity domain complex - - - Hemolysin domain

FigURE 5: Far-UV CD spectra of purified recombinant xenocinimmunity domain $(10 \mathrm{kDa})$ protein complex, catalytic-immunity domain protein complex, immunity protein, and its hemolysin domain.

protein of xenocin consists of 368 amino acid residues and is a unique fusion of two different domains. Its $\mathrm{N}^{\prime}$ terminal (first 85 amino acid residues) showed similarity with immunity protein from other prokaryotic systems, whereas the $C^{\prime}$ terminal showed similarity with hemolysin ( $N$. meningitidis accession no. AAF42109) and purine NTPase like proteins.

Three-dimensional structure of xenocin has been recently deciphered by homology modelling in my lab [14]. It is a multidomain protein which consists of 576 amino acid residues. From its $\mathrm{N}^{\prime}$ terminal $1-327$ amino acid residues form translocation domain (T), 328-476 amino acid residues form the middle receptor domain $(\mathrm{R})$, and amino acid residues from 477-576 form the catalytic domain $(C)$ at the $C^{\prime}$ terminal [14].

While cloning $x \operatorname{cin} A$ gene alone in expression vector, not a single transformant was observed. One reason for this result could be the leaky expression of toxic xcinA gene. To address this question, $x$ cin $A$ gene was cloned along with $\mathrm{N}^{\prime}$ terminal immunity domain $(10 \mathrm{kDa})$ of $x i m B$ gene. When the recombinant protein from JC6 strain was purified by Ni-NTA chromatography, xenocin was visible in SDS-PAGE at position corresponding to $66 \mathrm{kDa}$ whereas immunity domain of immunity protein was observed below $14 \mathrm{kDa}$ protein marker. This result showed that $\mathrm{N}^{\prime}$ terminal immunity domain $(10 \mathrm{kDa})$ of immunity protein $(42 \mathrm{kDa})$ encoded by $x \operatorname{im} B$ gene is enough to bind with and neutralize the in vivo toxic effect of $x$ cinA gene. To confirm this result and to map the minimum functional domain of immunity protein required to abolish the $x \operatorname{cin} A$ gene toxicity in vivo, first 85 amino acids of immunity protein were cloned along with $x \operatorname{cin} A$ gene under its native promoter. Same growth profile of XIM strain (harboring pXIM) and GEM strain (harboring empty pGEM T-Easy vector) in the presence of mitomycin $C$ confirmed that first 85 amino acid residues of $x i m B$ gene were able to neutralize the toxic activity of xenocin in vivo. Further, purification of recombinant catalytic-immunity domain protein complex with Ni-NTA chromatography under native conditions from JC4 strain [13] confirmed the minimal domains of $x \operatorname{cin} A$ and $x i m B$ genes that could be expressed and purified.

As we were unable to express $x \operatorname{cin} A$ gene alone which is composed of translocation, receptor, and catalytic domain an attempt had been made to clone, express, and purify the translocation domain alone or along with receptor domain of $x \operatorname{cin} A$ gene. In native conformation, translocation domain of bacteriocin like colicin E3 interacts with catalytic domain of E3 and immunity protein via receptor domain, and this interaction further provides stability to the translocation domain [15]. However, in recombinant translocation domain of $x \operatorname{cin} A$, receptor and catalytic domains as well as immunity protein were missing which may be probably made it to attain an open conformation and be susceptible to proteases from the host cells. Hence, during the purification of translocation domain from pJC8, multiple bands were observed in SDS-PAGE. However, western blot with purified fraction when probed with anti-His antibody showed a single band corresponding to the size of translocation domain which confirmed the expression of translocation domain alone. Further, purification of recombinant translocation-receptor domain protein with Ni-NTA chromatography from JC10 strain, showed two prominent bands in SDS-PAGE rather than multiple bands. Upper band corresponded to $\sim 52 \mathrm{kDa}$ whereas lower band corresponded to $\sim 28 \mathrm{kDa}$. western blot using whole cells and purified fraction when probed with anti-His antibody showed a single band at $52 \mathrm{kDa}$ which is corresponding to a size of recombinant translocationreceptor domain protein. Therefore, we inferred that recombinant translocation domain along with receptor domain of the $x \operatorname{cin} A$ gene was more stable as compared to the recombinant translocation domain alone, but due to the absence of catalytic domain and immunity protein it was still prone to proteases of the host cell.

Endogenous toxicity assays with XIM and GEM strains were performed to identify the minimum domain required to neutralize the $x \operatorname{cin} A$ toxicity. Results showed that first 85 amino acids of the immunity protein were able to neutralize xenocin endogenous toxicity as both strains had the same growth profile. Moreover, from this experiment we inferred that expression of cognate immunity protein domain and its binding to the catalytic domain of xenocin occurs in the host cell simultaneously.

Receptor domain in bacteriocin plays a major role in the exogenous toxic effect, as it is the first domain which binds to ligand present on the surface of its target cells. Binding is followed by import of bacteriocin into the cells with the assistance of either Ton proteins (ExbB, ExbD, and TonB) or Tol proteins (TolA, $-\mathrm{B},-\mathrm{Q}$, and $-\mathrm{R}$ ) of periplasm and facilitate the translocation of the catalytic domain of bacteriocins into the periplasmic space of the target cell for further processing [5, 16-18]. Interaction of bacteriocins either with Ton or Tol proteins of periplasm occurs via Ton or Tol box present at their $\mathrm{N}^{\prime}$ terminal end of the translocation domain. Bacteriocins with RNase activity generally have Tol box in their translocation domain [4]. Interestingly, although xenocin has RNase activity, Tol box in its translocation 
domain has been replaced by Ton box [13]. This could be due to the domain swapping which generally occurs during the horizontal gene transfer in prokaryotes [4]. In the colicin E3-immunity complex, binding of the receptor domain of $\mathrm{E} 3$ to the surface protein on target cells leads to the conformational changes which assisted the immunity protein to dissociate from the protein complex $[4,18]$. The immunity protein from $X$. nematophila is a unique fusion of immunity domain $(10 \mathrm{kDa})$ and hemolysin domain $(32 \mathrm{kDa})$ protein, and endogenous assay confirmed that immunity domain of $x i m B$ gene is enough to neutralize the detrimental effect of $x \operatorname{cin} A$ gene. Therefore, exogenous assay was performed with purified recombinant xenocin-immunity domain $(10 \mathrm{kDa})$ complex using E. coli $\mathrm{DH} 5 \alpha$ as target cells to determine translocational ability of xenocin-immunity domain $(10 \mathrm{kDa})$ complex into the cytoplasm of target cells. Clear zone of inhibition was observed in the exogenous toxicity assay due to the detrimental effect of xenocin-immunity domain $(10 \mathrm{kDa})$ protein complex. This result confirmed the functionality of translocation as well as receptor domain of xenocin and their individual roles in internalization of xenocin into the cytoplasm of target cells. Moreover, it also confirmed that hemolysin domain $(32 \mathrm{kDa})$ of $x \mathrm{imB}$ gene has no role in the internalization of xenocin as well as in exogenous toxicity.

Catalytic domain of $x \operatorname{cin} A$ gene along with immunity domain of $x i m B$ gene was the minimum domain which could be expressed and purified. Therefore, purified catalyticimmunity domain protein complex was studied for the bacteriostatic effect in the exogenous assays. Results showed that zone of inhibition was not observed, which again confirmed the role of translocation as well as receptor domain of $x$ cin $A$ gene for its internalization into the cytoplasm on the target cells. Similar results were observed when full length immunity protein $(42 \mathrm{kDa})$ encoded by $x \mathrm{imB}$ gene or its hemolysin domain $(32 \mathrm{kDa})$ was used for exogenous assay. Moreover, as expected zone of inhibition was not observed in the experiment in which buffer was used as a negative control.

To neutralize the detrimental effect of bacteriocins, they are always expressed along with cognate immunity protein [3]. The molecular weight of the immunity protein in other prokaryotic systems is between 10 and $16 \mathrm{kDa}$; [4] however, immunity protein encoded by ximB gene corresponds to $42 \mathrm{kDa}$. Protein-protein blast using BLASTP (http://www.ncbi.nlm.nih.gov/BLAST/) of the immunity protein showed similarity with hemolysin (AAF42109) and purine NTPase like protein. Hemolytic assay with fresh rabbit red blood cells was performed with purified full length immunity protein as well as its immunity and hemolysin domains. Due to the partial primary amino acid sequence similarity with hemolysin protein, none of the protein/protein domains showed hemolytic activity.

As immunity protein also showed similarity with protein like purine NTPase's ATPase assay was performed with purified recombinant full length immunity protein, its immunity domain, and hemolysin domain. Although full length immunity protein showed ATPase activity, in silico analysis did not show Walker motif in its primary amino acid sequence, which is generally present in the proteins having ATPase activity [19]. The role of ATPase activity in the recombinant immunity protein is still not understood. Possibility of ATPase activity in immunity protein towards the secretion of recombinant xenocin-immunity protein complex cannot be ruled out at this stage as none of the proteins have any signal sequence at their either ends.

Secondary structure analysis of purified recombinant xenocin-immunity domain $(10 \mathrm{kDa})$ protein complex, catalytic-immunity domain protein complex, immunity, and its hemolysin domain was done with far UV spectra. High percentage of $\alpha$-helical structure of xenocin-immunity complex is attributed due to the helix turn helix structure of receptor domain of xenocin which corroborates with its recently deciphered three-dimensional structure [14]. Catalytic-immunity domain protein complex was found to contain $51 \% \beta$-sheet and only $7 \% \alpha$-helical structure. This open conformation with high $\beta$-sheet might be beneficial to bind with its substrate (RNA) and act upon it $[20,21]$. In case of full length immunity protein $30 \%$ of the secondary structure was $\alpha$-helical where as $13 \%$ was $\beta$-sheet. Hemolysin domain of the immunity protein also had the same secondary conformation with $30 \% \alpha$-helical and $11 \% \beta$-sheet content. Since immunity protein is a novel fusion of two different domains the role of its secondary is not deciphered yet.

\section{References}

[1] D. Gordon, E. Oliver, and J. Littlefield-Wyer, "The diversity of bacteriocins in Gram-negative bacteria," in Bacteriocins, M. A. Riley and M. A. Chavan, Eds., Springer, 2007.

[2] M. A. Riley and J. E. Wertz, "Bacteriocin diversity: ecological and evolutionary perspectives," Biochimie, vol. 84, no. 5-6, pp. 357-364, 2002.

[3] E. Cascales, S. K. Buchanan, D. Duché et al., "Colicin biology," Microbiology and Molecular Biology Reviews, vol. 71, no. 1, pp. 158-229, 2007.

[4] L. Cursino, J. Šmarda, E. Chartone-Souza, and A. M. A. Nascimento, "Recent updated aspects of colicins of enterobacteriaceae," Brazilian Journal of Microbiology, vol. 33, no. 3, pp. 185-195, 2002.

[5] J. Singh and C. Ghosh, "Ribosomal encoded bacteriocins: their functional insight and applications," Journal of Microbiology Research, vol. 2, pp. 19-25, 2012.

[6] N. E. Boemare and R. J. Akhurst, "Biochemical and physiological characterization of colony form variants in Xenorhabdus spp. (Enterobacteriaceae)," Journal of General Microbiology, vol. 134, no. 3, pp. 751-761, 1988.

[7] E. E. Herbert and H. Goodrich-Blair, "Friend and foe: the two faces of Xenorhabdus nematophila," Nature Reviews Microbiology, vol. 5, no. 8, pp. 634-646, 2007.

[8] R. J. Akhurst, "Bacterial symbionts of entomopatho-genic nematodes: the power behind the throne," in Nematodes and the Biological Control of Insect Pests, R. Bedding, R. Akhurst, and H. Kaya, Eds., pp. 127-136, CSIRO Publications, Melbourne, Australia, 1993.

[9] H. K. Kaya and R. Gaugler, "Entomopathogenic nematodes," Annual Review of Entomology, vol. 38, pp. 181-206, 1993.

[10] R. J. Akhurst, "Antibiotic activity of Xenorhabdus spp., bacteria symbiotically associated with insect pathogenic nematodes of the families Heterorhabditidae and Steinernematidae," Journal of General Microbiology, vol. 128, no. 12, pp. 3061-3065, 1982. 
[11] K. H. Nealson, T. M. Schmidt, and B. Bleakley, "Physiology and biochemistry of Xenorhabdus," in Entomopathogenic Nematodes in Biological Control, R. Gaugler and H. Kaya, Eds., pp. 271-284, CRC Press, Boca Raton, Fla, USA, 1990.

[12] G. A. Couche and R. P. Gregson, "Protein inclusions produced by the entomopathogenic bacterium Xenorhabdus nematophilus subsp. nematophilus," Journal of Bacteriology, vol. 169, no. 11, pp. 5279-5288, 1987.

[13] J. Singh and N. Banerjee, "Transcriptional analysis and functional characterization of a gene pair encoding iron-regulated xenocin and immunity proteins of Xenorhabdus nematophila," Journal of Bacteriology, vol. 190, no. 11, pp. 3877-3885, 2008.

[14] J. Singh, "Structural and functional interferences from a molecular structural model of Xenocin Toxin from Xenorhabdus nematophila," American Journal of Bioinformatics Research, vol. 2, pp. 55-60, 2012.

[15] S. Soelaiman, K. Jakes, N. Wu, Li. Chunmin, and M. Shoham, "Crystal structure of colicin E3: implications for cell entry and ribosome inactivation," Molecular Cell, vol. 8, no. 5, pp. 10531062, 2001.

[16] M. de Zamaroczy, L. Mora, A. Lecuyer, V. Géli, and R. H. Buckingham, "Cleavage of colicin D is necessary for cell killing and requires the inner membrane peptidase LepB," Molecular Cell, vol. 8, pp. 159S-168S, 2001.

[17] S. D. Zakharov and W. A. Cramer, "Colicin crystal structures: pathways and mechanisms for colicin insertion into membranes," Biochimica et Biophysica Acta, vol. 1565, no. 2, pp. 333346, 2002.

[18] C. Liao, K. Hsiao, Y. Liu, P. Leng, H. S. Yuen, and K. Chak, "Processing of DNase domain during translocation of colicin E7 across the membrane of Escherichia coli," Biochemical and Biophysical Research Communications, vol. 284, no. 3, pp. 556562, 2001.

[19] C. Ramakrishnan, V. S. Dani, and T. Ramasarma, "A conformational analysis of Walker motif A [GXXXXGKT (S)] in nucleotide-binding and other proteins," Protein Engineering, vol. 15, no. 10, pp. 783-798, 2002.

[20] K. Hsia, C. Li, and H. S. Yuan, "Structural and functional insight into sugar-nonspecific nucleases in host defense," Current Opinion in Structural Biology, vol. 15, no. 1, pp. 126-134, 2005.

[21] D. Walker, L. Lancaster, R. James, and C. Kleanthous, "Identification of the catalytic motif of the microbial ribosome inactivating cytotoxin colicin E3," Protein Science, vol. 13, no. 6, pp. 1603-1611, 2004. 

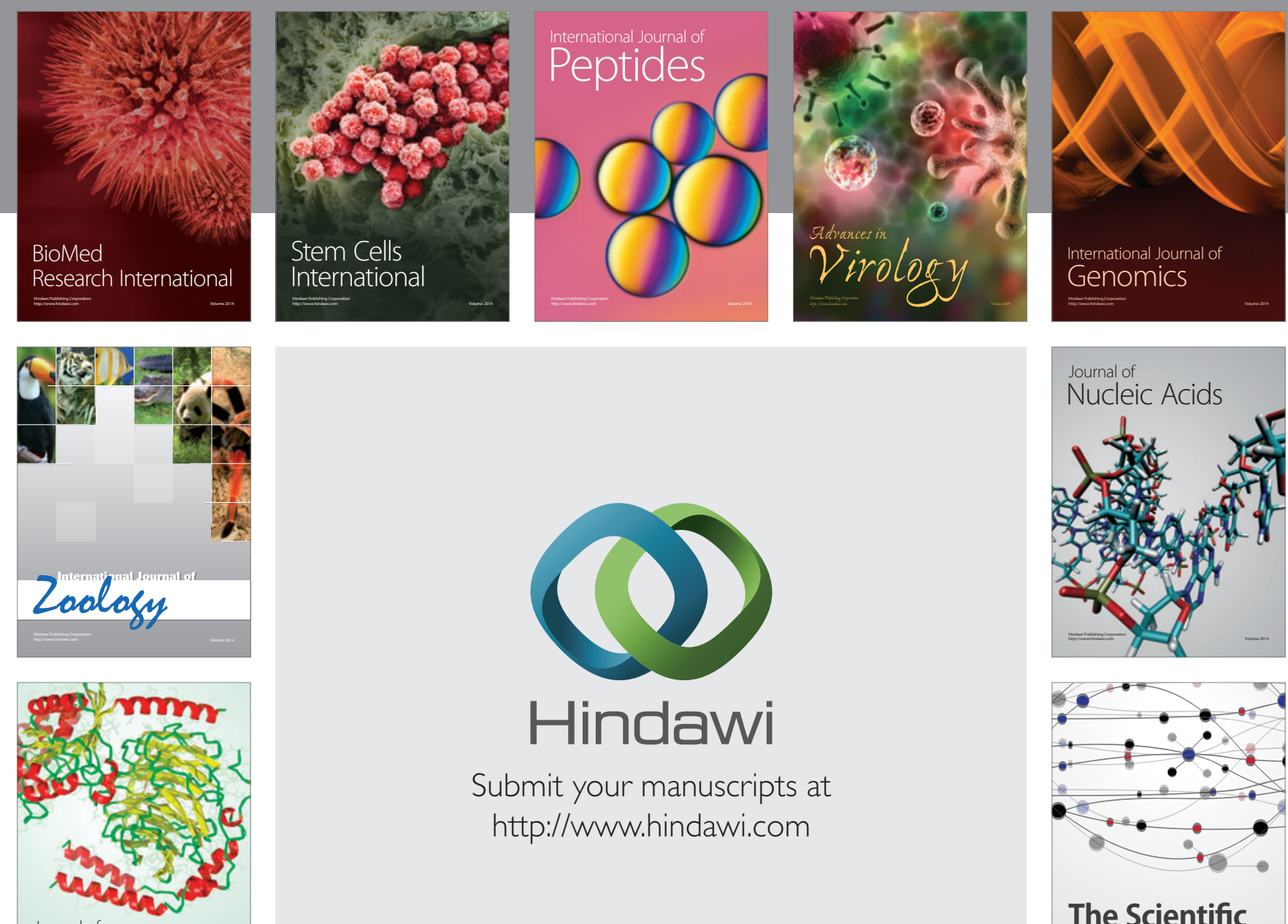

Submit your manuscripts at

http://www.hindawi.com

Journal of
Signal Transduction
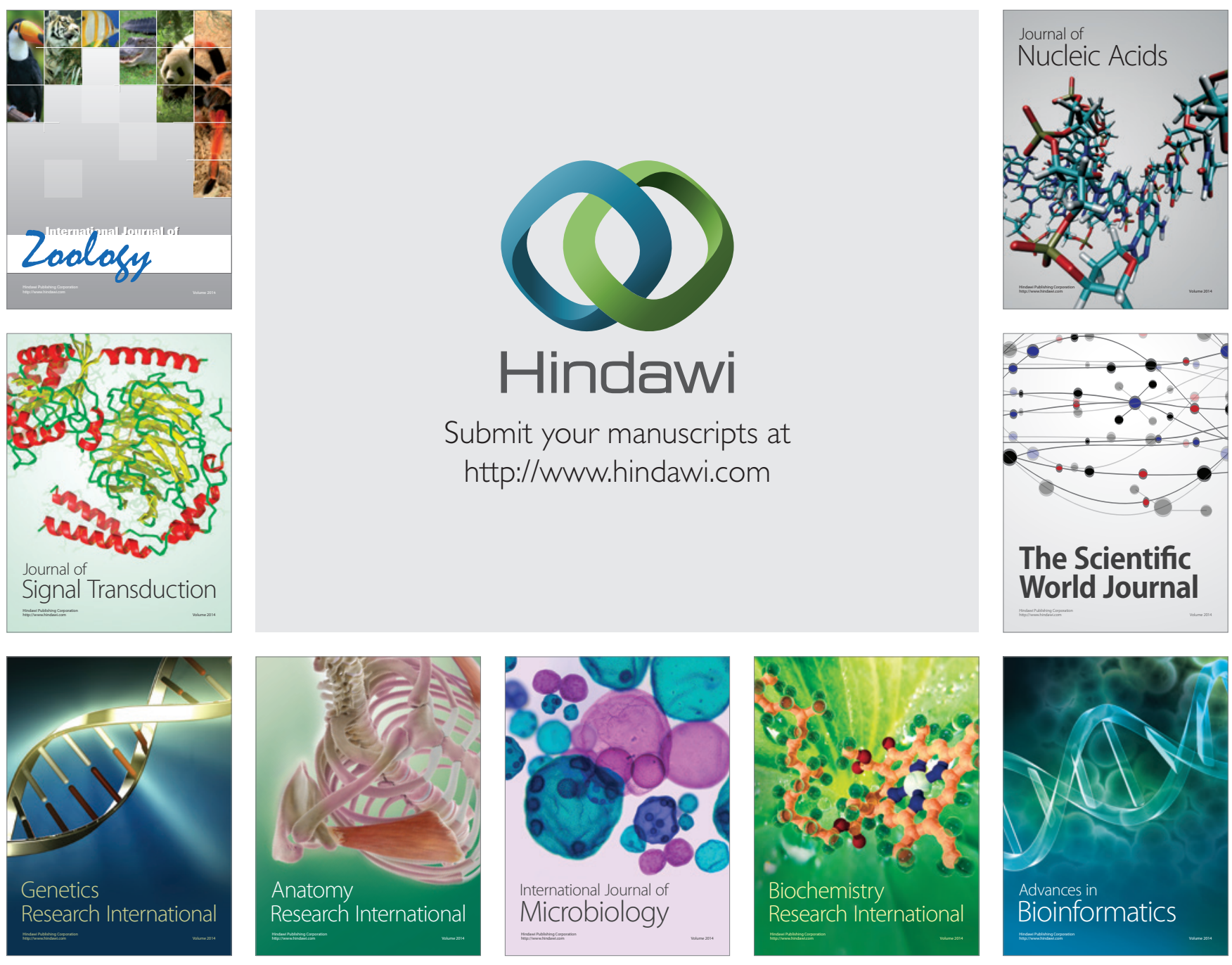

The Scientific World Journal
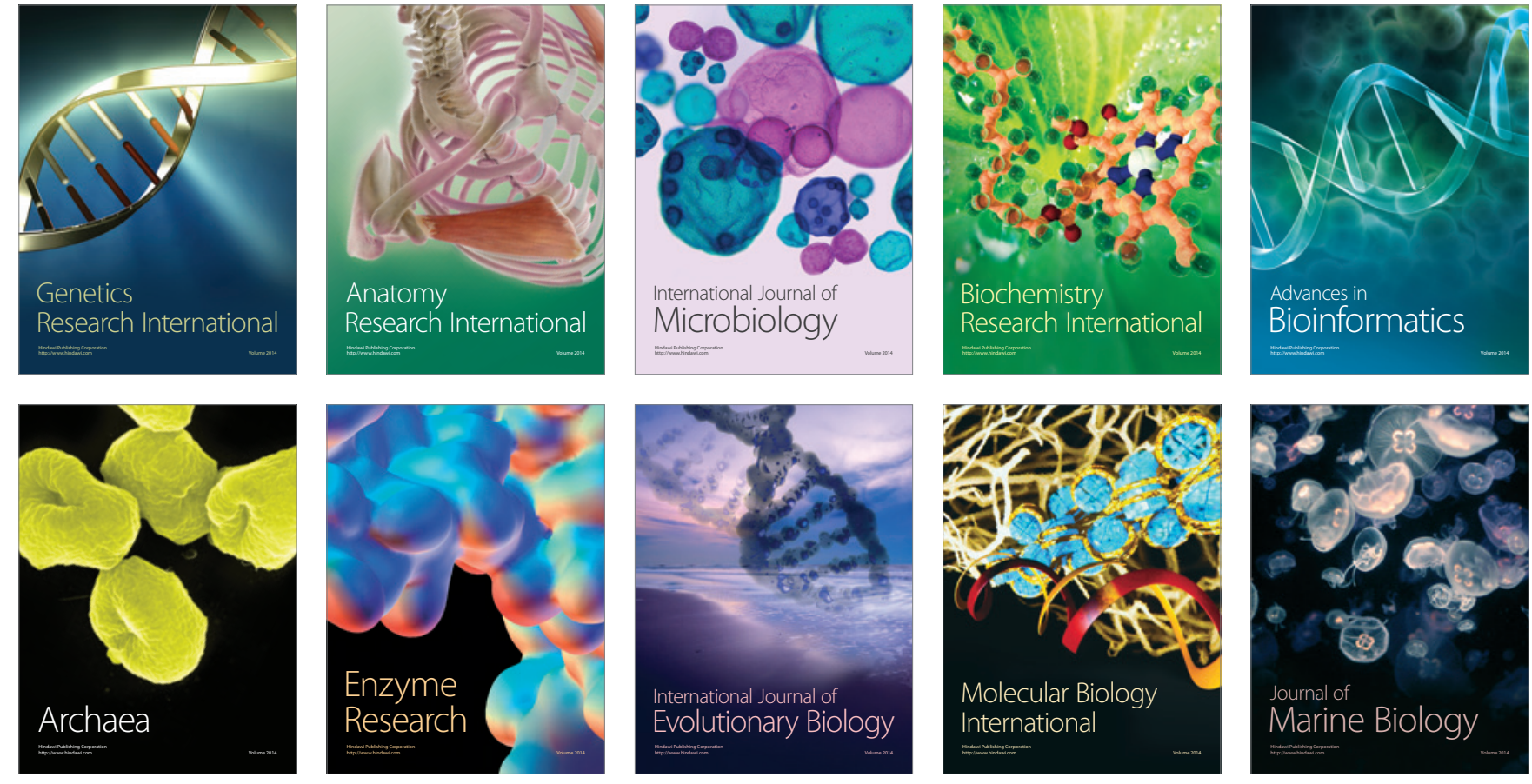